\title{
Full-Scale Experimental Investigation of the Static and Dynamic Stiffness of Prestressed Concrete Girders
}

\author{
Yongjun Zhou $\mathbb{D}^{D}$, Yu Zhao $\mathbb{D}^{D}$, Hengying Yao ${ }^{(D)}$, and Yuan Jing $(\mathbb{D}$ \\ School of Highway, Chang'an University, Xi'an, Shaanxi Province 710064, China \\ Correspondence should be addressed to Yongjun Zhou; zyj@chd.edu.cn
}

Received 4 June 2019; Revised 11 August 2019; Accepted 9 November 2019; Published 4 December 2019

Academic Editor: Giuseppe Ruta

Copyright ( 2019 Yongjun Zhou et al. This is an open access article distributed under the Creative Commons Attribution License, which permits unrestricted use, distribution, and reproduction in any medium, provided the original work is properly cited.

Cracking damage influences the stiffness of the girders. Many articles in the literatures have studied the development of stiffness of the scale-down model; however, full-scale model testing cannot be completely replaced by scale-down testing because of material component characteristics and boundary effects. This paper deals with the effects of cracking damage on the structural static and dynamic stiffness based on three prestressed concrete (PC) girders which were removed from an old bridge. First, the equivalent flexural rigidity of cracked prestressed concrete girder was assessed using the measured load-deflection response under cycles of loading and unloading. Then, after unloading, the frequencies were measured on the PC girders supported by the elastomeric bearings. Next, the development of frequency under different damage was studied, and finally, the dynamic stiffness of PC girders with cracks was assessed. The results indicate that the first frequency is more sensitive to the cracking of concrete compared with the second frequency and that the mode shapes are not sensitive to girder damage. The test girders cannot be simplified as an ideal simply supported beam for the purpose of identifying frequencies. In addition, the "final" (the end of the ultimate load case) equivalent flexural rigidity of the girders is $30 \%$ of the "initial" (the beginning of the first load case) equivalent flexural rigidity, compared with $50 \%$ in the scale-down test; and the final dynamic stiffness is approximately $84 \%$ of the initial dynamic stiffness, whereas the scale-down test is $72 \%$.

\section{Introduction}

Prefabricated prestressed concrete (PC) girders are widely used in bridge engineering. However, the durability of PC structures deteriorates due to the continuous accumulation of structural damage during its service life, such as cracking. Determining the effect of cracking damage on girder stiffness and service limit states is an important task in civil engineering.

Stiffness is a fundamental property that governs the behavior of cracked girders. When a cracked reinforced concrete (RC) member is subjected to loading, the moment of inertia of section (i.e., second moment of area) is degraded due to cracking and poor bonding between steel and concrete. These effects must be considered in the serviceability analysis of existing cracked RC members $[1,2]$. Concrete cracking reduces the stiffness of a structure, which influences not only its static behavior but also its dynamic response $[3,4]$. Xu and Castel studied the effects of steel-concrete bond damage on the dynamic stiffness of cracked RC beams under low-amplitude vibration. They found that considering the effect of bending cracks and neglecting the steel-concrete bond loss were in good agreement with both free and lowamplitude forced vibration test results [5], and they also found that localized steel-concrete bond damage did not influence the dynamic stiffness or natural frequency of a beam significantly, with or without sustained loading [6]. Das et al. found that the vibration mode shape and frequency of a structure changed after the structure was damaged. Additionally, the variation ratio between static stiffness and dynamic stiffness changed during the process of structural damage [7]. According to changes in frequency and mode shape, a method had been proposed for identifying damage degrees based on damage profiles $[8,9]$.

It is well known that frequency is closely related to boundary conditions. Musiał considered two types of boundary conditions for dynamic testing and compared measured modes to theoretical modes. There were considerable differences 
between the theoretical and measured mode shapes for simply supported beams [10]. Capozucca performed experimental research on real-scale $\mathrm{PC} / \mathrm{RC}$ beam models using vibration tests on free-free end condition beams. Frequency values in dynamic tests on PC beams varied linearly between $1 \%$ and $5 \%$ for the first mode of vibration, maintaining the beam in the elastic phase even if concrete was cracked due to tensile stresses [11]. Capozucca also performed nondestructive testing based on experimental vibration analysis of RC beams in a laboratory. Two beams were tested with free-free end conditions and two others with hinge-hinge end conditions. The results revealed the first frequency difference between the theoretical calculations and experimental data under free-free end conditions was $8.33 \%$, and the second frequency difference was $11.16 \%$ [12]. There are also significant differences when using hinge-hinge boundary conditions to simulate the boundary conditions of practical girders. Much consideration was given to the support conditions used in the dynamic tests, and it was deemed inappropriate to test the beams in the free condition. This was partly for the practical reasons: the size and weight of the specimens made it difficult to do so, and what is more, it would not be possible to create these conditions for the practical engineering.

Nowadays, few full-scale tests were conducted owing to many reasons such as high testing expenses and the rare availability of testing subjects. Due to the observed difference between the original designs and the tested bridges, some researchers pointed out that more studies were needed to understand the real performance of bridges in the field [13].

The aim of this study is to identify dynamic stiffness under elastic boundary conditions and to explore the relationship between stiffness and crack damage. Three prefabricated PC girders were removed from a decommissioned bridge, and full-scale static and dynamic tests were carried out. The static and dynamic parameters of the girders under different damage conditions were obtained. In this study, the equivalent flexural rigidity of the test girders is assessed based on their load-deflection responses under cycles of loading and unloading. Additionally, the frequency is evaluated theoretically by assuming elastic boundary conditions. For each degree of damage, the fundamental natural frequency of each girder is measured to assess dynamic stiffness. Finally, the relationship between static and dynamic stiffness is analyzed.

\section{Static and Dynamic Stiffness Calculation Method}

Static and dynamic stiffness, in this paper, refer to the structural equivalent flexural rigidity and dynamic stiffness rather than specific section stiffness, and three assumptions are made: (1) The deformation of a girder follows the small deformation theory. (2) The equivalent flexural rigidity of a girder is constant under a specific load; that is, different loads lead to different equivalent flexural rigidity values. (3) The equivalent flexural rigidity is calculated by deflection, and the dynamic stiffness is calculated by natural frequency.
2.1. Equivalent Flexural Rigidity. A mechanical diagram of a symmetrical load applied to a simply supported girder is presented in Figure 1. The deflection of a simply supported girder can be written as follows:

$$
\delta=\frac{P a\left(3 L^{2}-4 a^{2}\right)}{48 E I_{s}},
$$

where $\delta$ is the deflection in the midspan of the girder, $P$ is the concentrated force, $L$ is the span length, $a$ is the distance from the support to the concentrated force, $E$ is the elastic modulus of concrete, $I_{s}$ is the average inertia moment of the cross section, and $E I_{s}$ is the equivalent flexural rigidity of the girder.

So, the equivalent flexural rigidity of the structure can be obtained:

$$
E I_{s}=\frac{P a\left(3 L^{2}-4 a^{2}\right)}{48 \delta}
$$

2.2. Dynamic Stiffness. For a bending girder, only the vertical displacement $y$ is of interest. This displacement is a function of coordinate $x$ and time $t$. The inertial force of the girder is supposed to be $\rho \cdot A \cdot\left(\left(\partial^{2} y(x, t)\right) / \partial t^{2}\right)$, where $\rho$ is the density of the girder and $A$ is the cross-sectional area. The following equation describes the free vibration of a girder:

$$
E I_{d} \cdot \frac{\partial^{4} y(x, t)}{\partial x^{4}}+\rho \cdot A \cdot \frac{\partial^{2} y(x, t)}{\partial t^{2}}=0
$$

where $E I_{d}$ is the equivalent dynamic stiffness of the girder.

The vertical displacement $y(x, t)$ can be written as

$$
y(x, t)=\varphi(x) \cdot \sin (\omega t+\theta),
$$

where $\varphi(x)$ is the mode shape, $\omega$ is the circular natural frequency, and $\theta$ is the phase angle.

By substituting equation (4) into equation (3) and assuming $\alpha^{4}=\rho \cdot A \cdot \omega^{2} / E I_{d}$, the following equation can be obtained:

$$
\frac{\mathrm{d}^{4} \varphi(x)}{\mathrm{d} x^{4}}+\alpha^{4} \cdot \varphi(x)=0 .
$$

A general solution of the differential equation (5) can be written as follows:

$\varphi(x)=C_{1} \sin (\alpha x)+C_{2} \cos (\alpha x)+C_{3} \sinh (\alpha x)+C_{4} \cosh (\alpha x)$,

where $C_{i}(i=1,2,3,4)$ is a constant to be determined according to the boundary conditions.

The boundary conditions in full-scale tests follow an elastic constraint model, as shown in Figure 2, where the following boundary conditions must be considered:

$$
\begin{aligned}
& \left.E I_{d} \varphi^{\prime \prime}\right|_{x=0}=-\left.K_{L} \varphi^{\prime}\right|_{x=0}, \\
& \left.E I_{d} \varphi^{\prime \prime \prime}\right|_{x=0}=-\left.k_{L} \varphi\right|_{x=0}, \\
& \left.E I_{d} \varphi^{\prime \prime}\right|_{x=L}=-\left.K_{R} \varphi^{\prime}\right|_{x=L}, \\
& \left.E I_{d} \varphi^{\prime \prime \prime}\right|_{x=L}=-\left.k_{R} \varphi\right|_{x=L},
\end{aligned}
$$




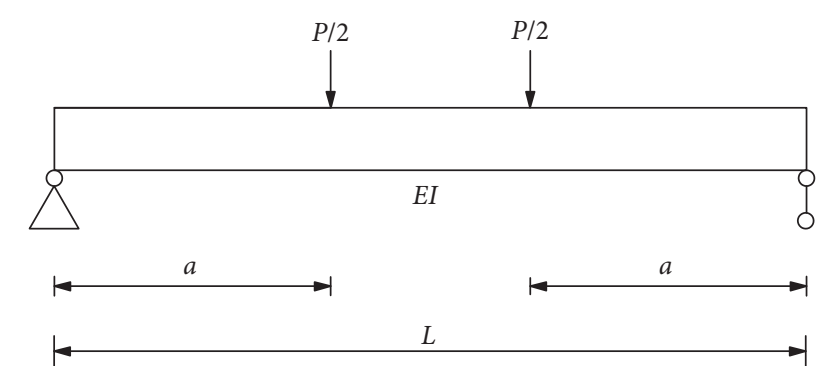

Figure 1: Mechanical diagram of a simply supported girder under symmetrical loading.

where $K$ is the stiffness of a rotational restraint spring, $k$ is the stiffness of a linear restraint spring, and the subscripts $L$ and $R$ denote the left and right ends of the girder, respectively. In this study, the stiffness of the linear restraint spring refers to the vertical stiffness of the elastomeric bearing. Typically, in a simply supported girder, the stiffness of the rotational restraint spring equals to zero.

In matrix form, the following unknown vector $\underline{Z}$ is proposed:

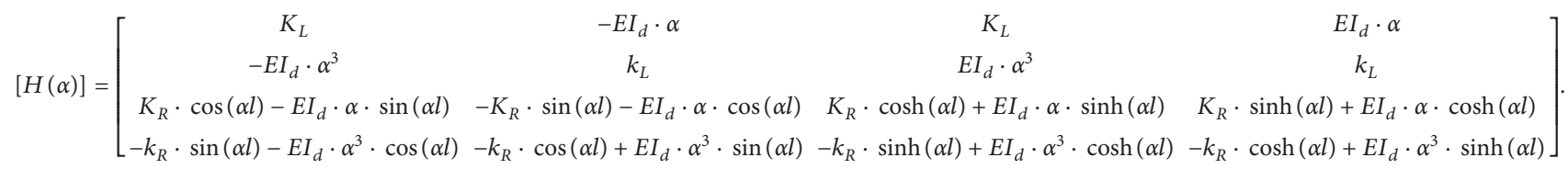

If the vector $\underline{Z}$ has a nonzero solution, then the determinant of the coefficient matrix should be null, meaning $|H(\alpha)|=0$. Then, the following expression for the frequency $\omega_{i}$ of vibration mode $i$ can be obtained for a case with elastic boundary conditions:

$$
\omega_{i}=\beta_{i}\left(\frac{i \pi}{L}\right)^{2} \sqrt{\frac{E I_{d}}{\rho A}}, \quad i=1,2, \ldots,
$$

where $\beta_{i}$ depends on the modes of vibration and boundary conditions. When the stiffness of the linear restraint spring $k$ is infinite, which meets the idealized conditions for a simply supported girder, $\beta_{i}$ should equal to 1 .

According to equation (11), the dynamic stiffness of the girders based on the measured fundamental frequency can be calculated as follows:

$$
E I_{d}=\frac{\rho A \omega_{1}^{2}}{\beta_{1}^{2}(\pi / L)^{4}} .
$$

\section{Experiments}

The objective of the experiments was to measure deflection and frequency to calculate the equivalent static and dynamic stiffness of full-scale girders that were subjected to loading and unloading cycles.

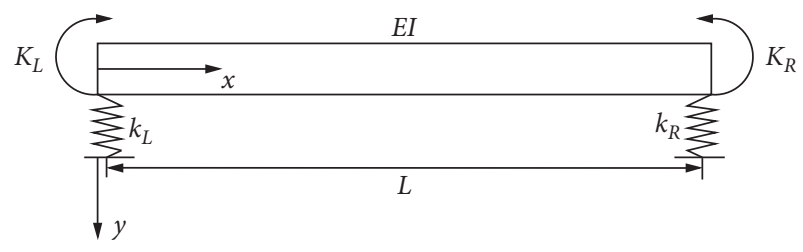

Figure 2: Elastic boundary conditions model of the girder.

$$
\underline{Z}=\left\{\begin{array}{l}
C_{1} \\
C_{2} \\
C_{3} \\
C_{4}
\end{array}\right\}
$$

Then, equation (7) becomes

$$
[H(\alpha)] \underline{Z}=\underline{0},
$$

where

3.1. Test Girders. Three PC girders denoted Z1, Z2, and B1 were removed from a 30-year-old bridge. Due to overloading, some transverse and longitudinal cracks occurred during its service life. After special inspection and bearing capacity evaluation, the bridge was suggested to be demolished.

There were different visible cracks in the test girders before their demolition, which are shown in Table 1 and Figure 3.

Figure 4 presents the test configuration of the girders. The specimens were $3000 \mathrm{~cm}$ in length and had box cross sections measuring $290 \mathrm{~cm}$ in width and $158 \mathrm{~cm}$ in height. The girders had almost the same uniform section except for 1.5 meters near each end. Girders Z1 and Z2 were reinforced with 28 prestressed tendons having diameters of $15.2 \mathrm{~mm}$. Girder B1 was reinforced with 35 prestressed tendons. The three girders were originally located at different positions and supported by elastomeric bearings, which were also removed from the bridge.

In the process of dismantling the girders, firstly, the guardrail and asphalt pavement were removed from the site; then the concrete and tendon at the continuous support were sawed, and the test girders and the elastomeric bearings both were removed from the site so that the boundary condition was close to that in situ. 
TABle 1: Cracks of the test girders.

\begin{tabular}{lcccccc}
\hline Girder & \multicolumn{2}{c}{ Transverse cracks } & \multicolumn{2}{c}{ Longitudinal cracks } \\
& Numbers & Max width $(\mathrm{mm})$ & Total length $(\mathrm{m})$ & Numbers & Max width (mm) & Total length $(\mathrm{m})$ \\
\hline Z1 & 4 & 0.1 & 2.87 & 4 & 0.15 & 7 \\
Z2 & 5 & 0.15 & 4.47 & 4 & 0.15 & 8 \\
B1 & 2 & 0.1 & 2 & 6 & 0.1 & 27 \\
\hline
\end{tabular}

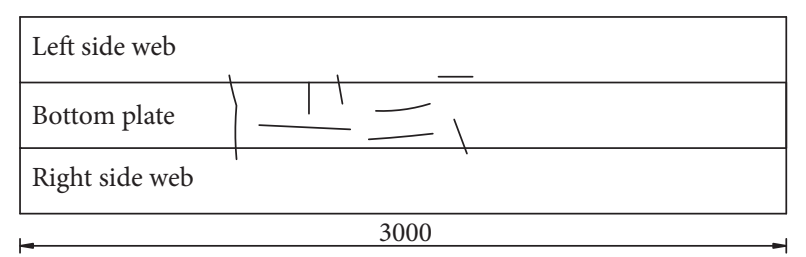

(a)

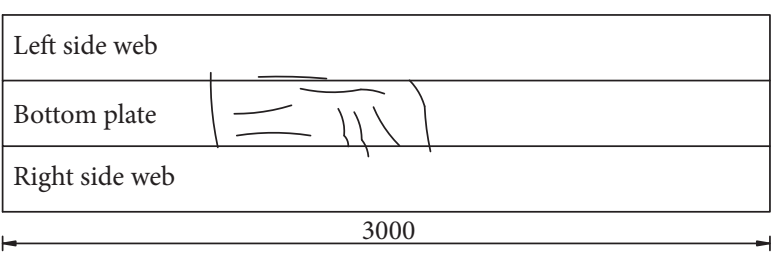

(b)

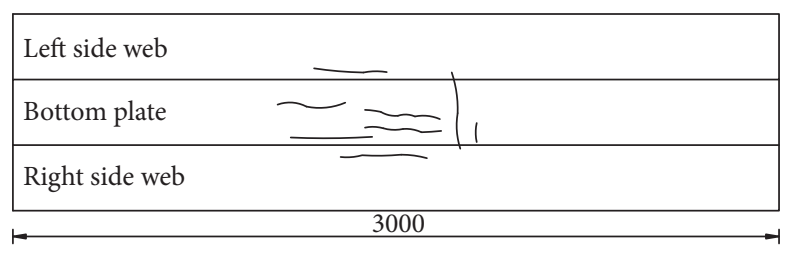

(c)

Figure 3: Visible cracks of the test girders (unit: cm). (a) Girder Z1. (b) Girder Z2. (c) Girder B1.

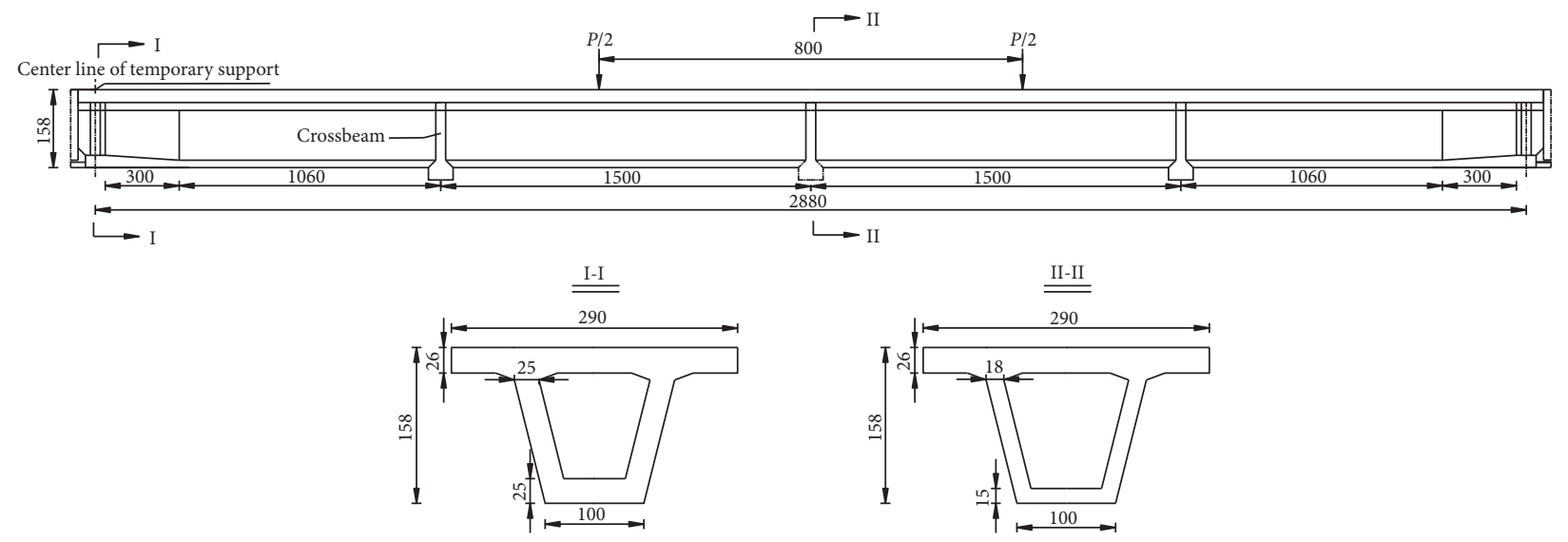

Figure 4: Test configuration of the girders (unit: $\mathrm{cm}$ ).

Cylindrical core drilling was sampled on the end of each girder after the accomplishment of the test, and the compressive strength and elastic modulus were tested. The compressive test of concrete is shown in Figure 5.

Test results of compressive strength of concrete are shown in Table 2. According to the standard for the test method of concrete structures published in 2012, the maximum and minimum values of concrete compressive strength should be removed from all measured results, and the rest of the test results should be averaged. Therefore, the average compressive strength of concrete is $30.1 \mathrm{MPa}$.

Elastic modulus tests of concrete are shown in Table 3. From the results in Table 3, it can be seen that the average measured elastic modulus is $31043 \mathrm{MPa}$.

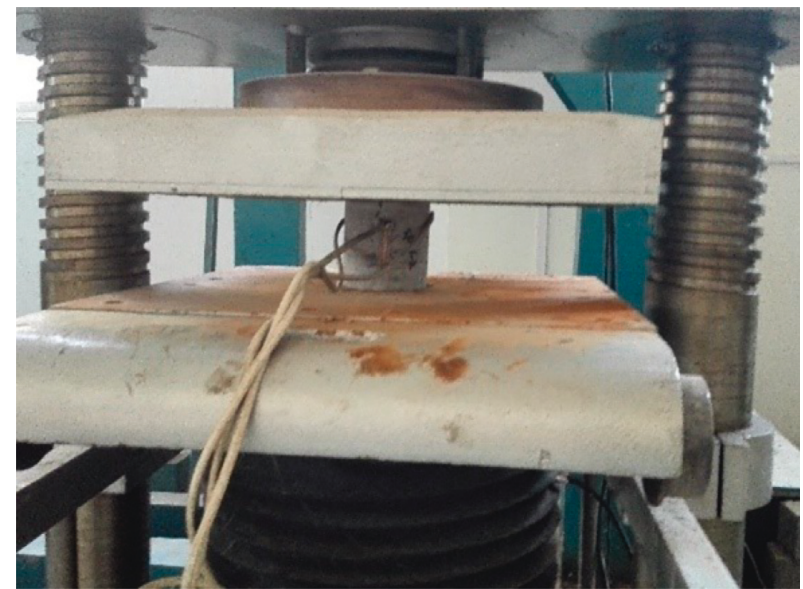

FIgURE 5: Compressive test of the concrete. 
TABLE 2: Compressive strength test results of concrete.

\begin{tabular}{lccc}
\hline $\begin{array}{l}\text { Sample } \\
\text { number }\end{array}$ & $\begin{array}{c}\text { Sample } \\
\text { height }(\mathrm{mm})\end{array}$ & $\begin{array}{c}\text { Sample } \\
\text { diameter }(\mathrm{mm})\end{array}$ & $\begin{array}{c}\text { Compressive } \\
\text { strength }(\mathrm{MPa})\end{array}$ \\
\hline Z1-1 & 100.9 & 99.2 & 31.2 \\
Z1-2 & 100.1 & 99.8 & 31.8 \\
Z1-3 & 101.1 & 99.6 & 33.3 \\
Z2-1 & 101.7 & 99.6 & 35 \\
Z2-2 & 100.8 & 100.2 & 27.8 \\
Z2-3 & 101.1 & 99.2 & 33.8 \\
Z2-4 & 101.5 & 100.6 & 39.3 \\
B1-1 & 100.6 & 99.1 & 25.1 \\
B1-2 & 100.6 & 99.2 & 20.5 \\
B1-3 & 101.6 & 99.8 & 30.3 \\
\hline
\end{tabular}

3.2. Static Tests. Static tests were performed on the three girders by increasing the load $P$ that was applied $800 \mathrm{~cm}$ from the centers of the girders. The test girders were subjected to five loading cycles that were controlled by the maximum crack width of concrete cracking caused by loads near midsection, which was detected by using a professional crack width measuring instrument. Each loading cycle was subdivided into three steps. The deflections were measured by using dial indicators. Two dial indicators were set up at the support, midspan, and quarterspan locations of the girders to measure their vertical deflection, respectively (Figure 6). The dial indicators at the support were mainly used to eliminate the influence of support settlement (ground surface) on structural deflection. The test site was casted with concrete before the experiment. The preloading test at the loading point (anchor pile) was carried out to eliminate the influence of inelastic ground surface movement; elastic movement of the ground surface can be neglected compared with the vertical deflection of the girder by theoretical analysis.

The deflection of the test girders is shown in Figure 7. The effective displacement under loading was calculated by the following equation:where $\delta_{e}$ is the effective measured deflection of girders under loads, $\delta_{t}$ is the total measured deflection of girders, $\delta_{r}$ is the measured residual deflection of girders, and $\delta_{c}$ is the measured settlement at both ends of girders.

$$
\delta_{e}=\delta_{t}-\delta_{r}-\delta_{c},
$$

Four ground-anchored piles, distribution girders, and hydraulic jacks were the main instruments used in the tests. Pressure sensors were placed under the hydraulic jacks to control the vertical load. A photograph of the loading device is presented in Figure 8.

3.3. Dynamic Tests. Dynamic tests were performed after the loads were removed from each static loading cycles. In the dynamic vibration tests, nine vertical acceleration sensors were arranged along the central line of the test girder (Figure 6), and 941B ultralow-frequency sensors were used. An ambient excitation method was adopted, and all the vibration signals were collected simultaneously. American IOtech, model: DAQ-208, was used as the data acquisition module. The vibration frequency was analyzed by the fast Fourier transform (FFT) technique in Dasylab 6.0, the sampling rate of which was $50 \mathrm{~Hz}$. The data was filtered by
TABLE 3: Elastic modulus tests results of concrete.

\begin{tabular}{lccc}
\hline $\begin{array}{l}\text { Sample } \\
\text { number }\end{array}$ & $\begin{array}{c}\text { Sample height } \\
(\mathrm{mm})\end{array}$ & $\begin{array}{c}\text { Sample diameter } \\
(\mathrm{mm})\end{array}$ & $\begin{array}{c}\text { Elastic modulus } \\
(\mathrm{MPa})\end{array}$ \\
\hline Z1-4 & 101.7 & 99.8 & 32523 \\
Z2-5 & 100.8 & 100.4 & 33520 \\
B1-4 & 100.4 & 99.4 & 28584 \\
B1-5 & 101.5 & 99.8 & 29548 \\
\hline
\end{tabular}

using the Butterworth digital filter. The low-pass filter's cutoff frequency was $40 \mathrm{~Hz}$. The first two mode shapes of the girders were obtained by the modal analysis method for environmental excitation experiments with the help of DH5925 software.

\section{Static Results}

When the displacement of the girder reached the hydraulic jack stroke range, there was no crushing on the compressive concrete or tendon breakage in the three girders, so the test was stopped. At this time, the maximum width of the cracks at the webs of girder Z1, girder Z2, and girder B1 was $1.2 \mathrm{~mm}$, $1.33 \mathrm{~mm}$, and $1.25 \mathrm{~mm}$, respectively. The ultimate loads for three girders were $1240 \mathrm{kN}, 1190 \mathrm{kN}$, and $1400 \mathrm{kN}$, respectively.

Table 4 lists the main experimental data from the static tests for different levels of crack damage $D_{i}$, which is defined as the maximum crack width caused by loads or different load cases (LCs).

Experimental diagrams for the load $P$ versus the deflection $\delta$ at the midspan locations of the three girders are presented in Figure 9, in which the deflection is the effective result of removing residual displacements and the settlements of the supports from the total measured values. At the beginning of each loading cycles, the deflection was adjusted to 0 , and it means that the deflections are shifted the original point to rank them.

From Figure 9, one can see that the midspan deflection of the three girders increases with the increasing load. During the cycles of loading and unloading, in the early stage of loading, the load deflection $P-\delta$ curves are approximately linear when the load is under $200 \mathrm{kN}$, and there is no visible increment of crack and no residual displacement, which demonstrates that the test girders are within the elastic stage. When the load increases to approximately $200 \mathrm{kN}$, the $P-\delta$ curves become nonlinear as the test girders enter an elasticplastic stage. Moreover, the slopes of the $P-\delta$ curves of the test girders decrease with load, indicating a decrease in flexural rigidity with an increasing load.

\section{Dynamic Results}

5.1. Experimental Frequency. The different frequencies of test girders after different damage conditions $D_{i}(i=1, \ldots, 4)$ for modes 1 and 2 are presented in Figure 10 and Table 5, in which a decrease of frequency with increased cracking damage is evident.

In Table 5, the variation rates of frequency is calculated as $\left(\Delta f_{r} / f_{r}^{D_{0}}\right)=100 \cdot\left(\left(f_{r}^{D_{0}}-f_{r}^{i}\right) / f_{r}^{D_{0}}\right)$, where $f_{r}^{D_{0}}$ is the frequency at undamaged condition $D_{0}$ for $r$ mode $(r=1,2)$ 


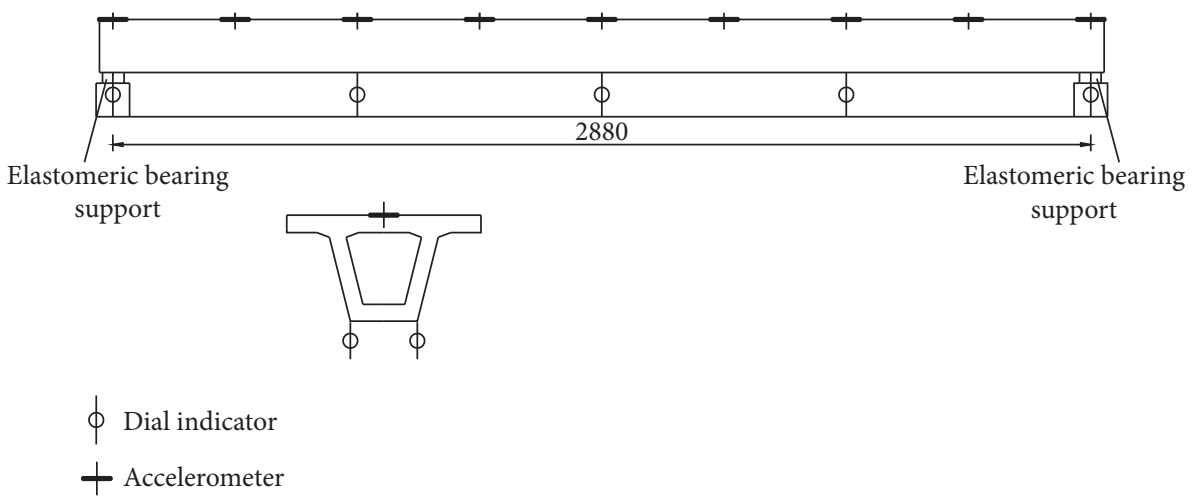

FIgURE 6: Layout of measurement points (unit: $\mathrm{cm}$ ).

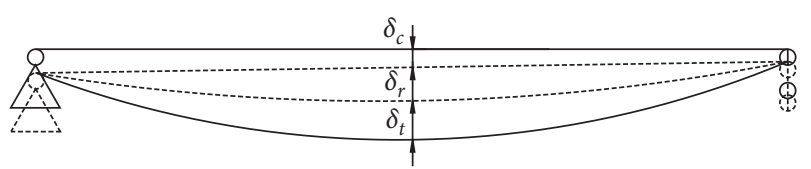

Figure 7: The deflection of the test girders.

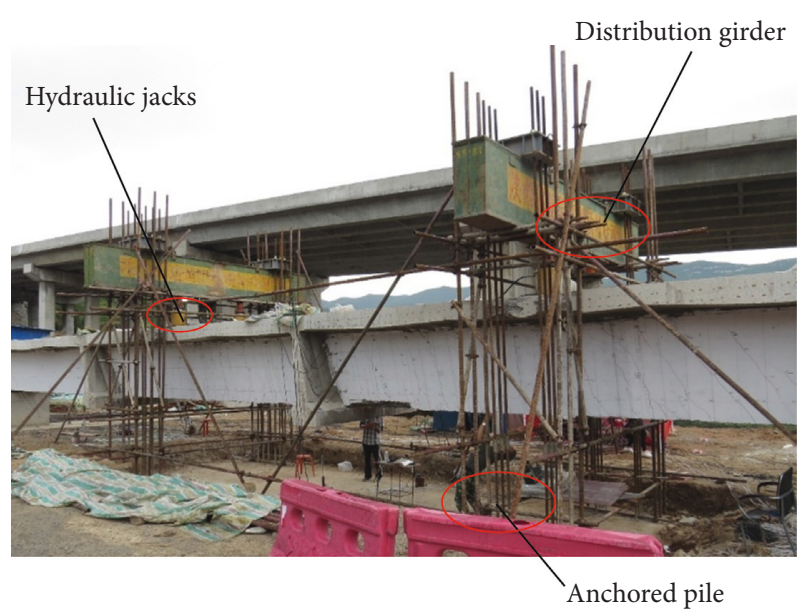

Figure 8: Loading device.

and $f_{r}^{i}$ is the frequency at different load cycles $D_{i}(i=1, \ldots, 4)$ for $r$ mode $(r=1,2)$ [14].

The first LC1 which is the first damage degree $D_{1}$ determines the expansion of cracking in the concrete under tensile strain area. Therefore, cracking in the concrete is a significant cause of the frequency reductions recorded in the experimental tests. It should be noted that the first frequency is reduced by approximately $2 \sim 6 \%$ in the first two LCs (damages $D_{1}$ and $D_{2}$ ). With an increase of damage, the decrease rates of both frequencies increase and $\Delta f_{1} / f_{1}^{D_{0}}$ become much larger than $\Delta f_{2} / f_{2}^{D_{0}}$, illustrating $f_{1}$ is more sensitive to cracks compared to $f_{2}$. The reason may be that the first mode shape of the test girders is symmetrical, and the cracking is severe near midspan, so the first curvature mode shape is greatly affected by the cracking. However, the second mode shape is antisymmetric, and the second curvature mode shape is less affected by the cracking in the midspan [15].

The final experiment frequencies of girders $\mathrm{Z} 1, \mathrm{Z} 2$, and B1 decrease $8.11 \%, 8.33 \%$, and $8.33 \%$, respectively, compared with the initial (damage condition $D_{0}$ ) ones. One can see that the ultimate variation rates in frequency for the three test girders are nearly the same. $D_{3}$ and $D_{4}$ show the same frequency, indicating that after a certain damage threshold, the frequency stabilizes.

The first and second frequency decrease rates of the full-scale tested girder are about $8 \%$ and $4 \%$, respectively. They are much smaller than the first frequency decrease rate $(20 \%)$ and the second frequency decrease rate $(8 \%)$ of the scale-down model beams, respectively [7]. However, Capozucca [11] described that frequency values in dynamic tests on PC beams varied linearly between $1 \%$ and $5 \%$ for the first mode of vibration. This shows that the results of the scale-down testing are controversial. The reason may be that the ratio of loading length to span length of full-scale girder and scale-down model beam is different, which leads to different distributions of damage state. In addition, the support conditions of the full-scale girder are different from those of the model beam in the laboratory, and these influencing factors on the frequencies of the structure are very complicated; that is, the spatial size effect has some influence on the dynamic response of the structure.

5.2. Experimental Mode Shape and Boundary Condition Identification. The first two mode shapes of girder $\mathrm{Z} 1$ prior to loading and under various LCs are presented in Figure 11. One can see that the mode shapes of the first two modes of the girder are slightly different under different LCs, but the difference is negligible. This indicates that the low-vibration mode shape is not sensitive to girder damage, which is basically consistent with the phenomenon of scale-down model beams [8]. Additionally, it is notable that the vertical displacement is not zero at the support, which is consistent with our theoretical analysis of the elastic constraint condition model. This demonstrates that the boundary conditions of the test girders are different from the idealized boundary conditions of a simply supported girder, which 
TABLE 4: Experimental data for girders subjected to cycles of static loading.

\begin{tabular}{|c|c|c|c|c|c|c|}
\hline Girder & Experimental parameters & $D_{0} / \mathrm{LC} 0$ & $D_{1} / \mathrm{LC} 1$ & $\mathrm{D}_{2} / \mathrm{LC} 2$ & $D_{3} / \mathrm{LC} 3$ & $D_{4} / \mathrm{LC} 4$ \\
\hline \multirow{3}{*}{$\mathrm{Z} 1$} & $P(\mathrm{kN})$ & 120 & 560 & 820 & 1160 & 1240 \\
\hline & $\delta$ deflection $(\mathrm{mm})$ & 5.0 & 35.78 & 97.54 & 150.49 & 164.62 \\
\hline & Crack width $(\mathrm{mm})$ & 0 & 0.31 & 0.65 & 0.99 & 1.20 \\
\hline \multirow{3}{*}{$\mathrm{Z} 2$} & $P(\mathrm{kN})$ & 72 & 520 & 840 & 1190 & 1190 \\
\hline & $\delta$ deflection $(\mathrm{mm})$ & 3.2 & 48.48 & 108.22 & 182.89 & 184.25 \\
\hline & Crack width $(\mathrm{mm})$ & 0 & 0.38 & 0.74 & 1.13 & 1.33 \\
\hline \multirow{3}{*}{ B1 } & $P(\mathrm{kN})$ & 51 & 580 & 920 & 1190 & 1400 \\
\hline & $\delta$ deflection $(\mathrm{mm})$ & 2.2 & 41.65 & 98.79 & 141.74 & 175.42 \\
\hline & Crack width $(\mathrm{mm})$ & 0 & 0.39 & 0.70 & 1.04 & 1.25 \\
\hline
\end{tabular}

$D_{0}$ is in the elastic stage for the test girders.

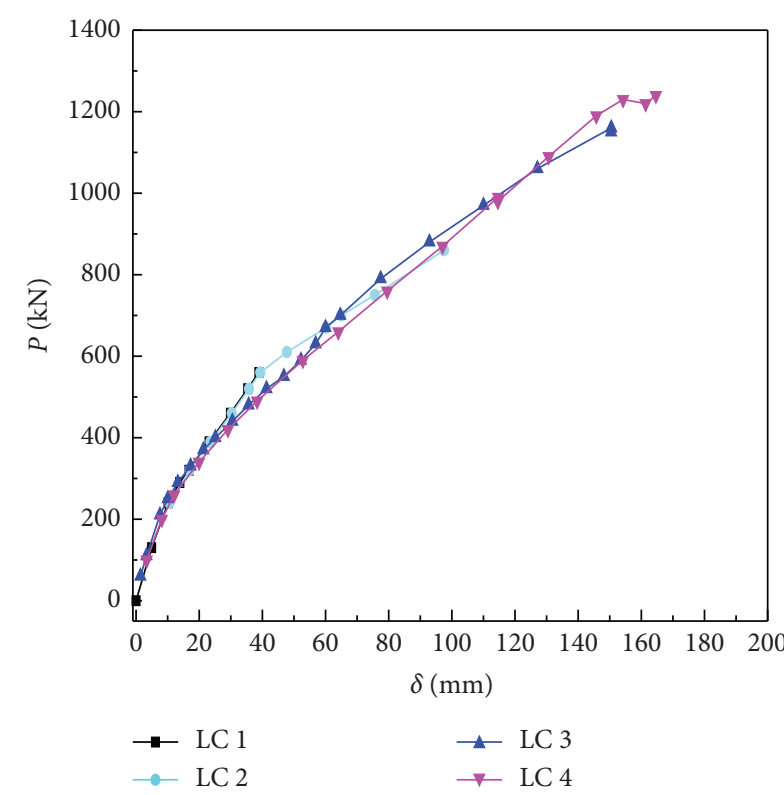

(a)

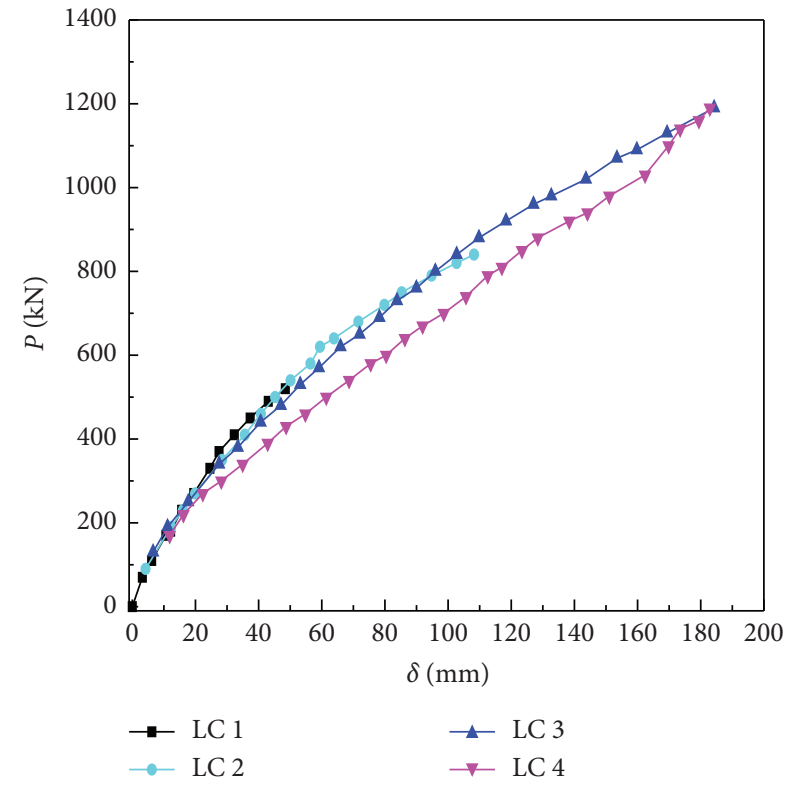

(b)

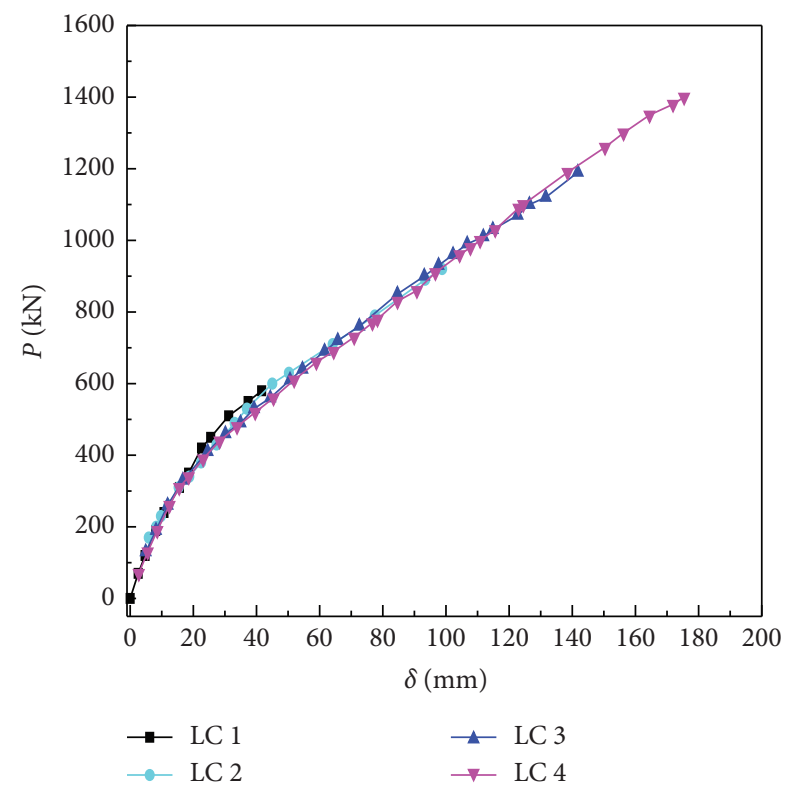

(c)

Figure 9: Relationship between load and deflection at the midspan locations. (a) Girder Z1. (b) Girder Z2. (c) Girder B1. 


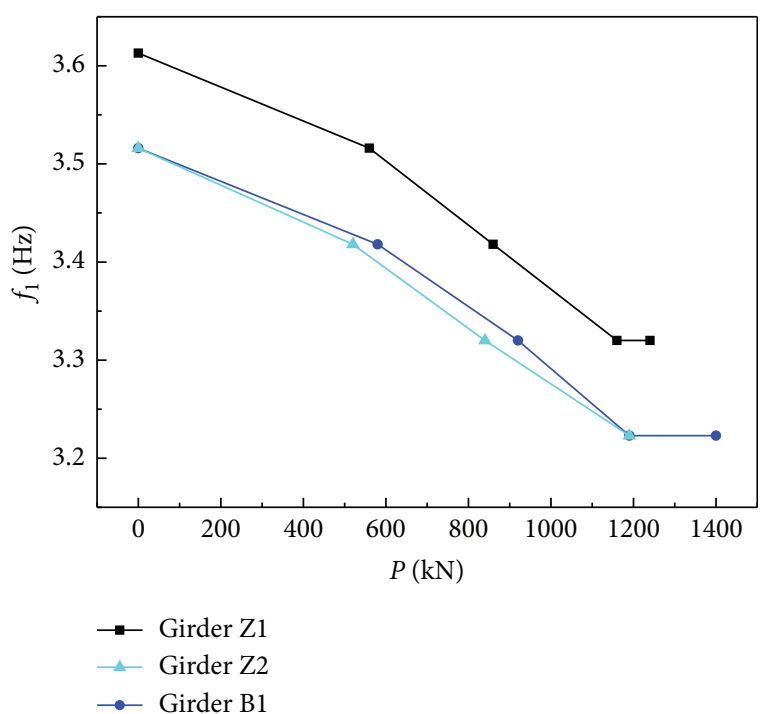

(a)

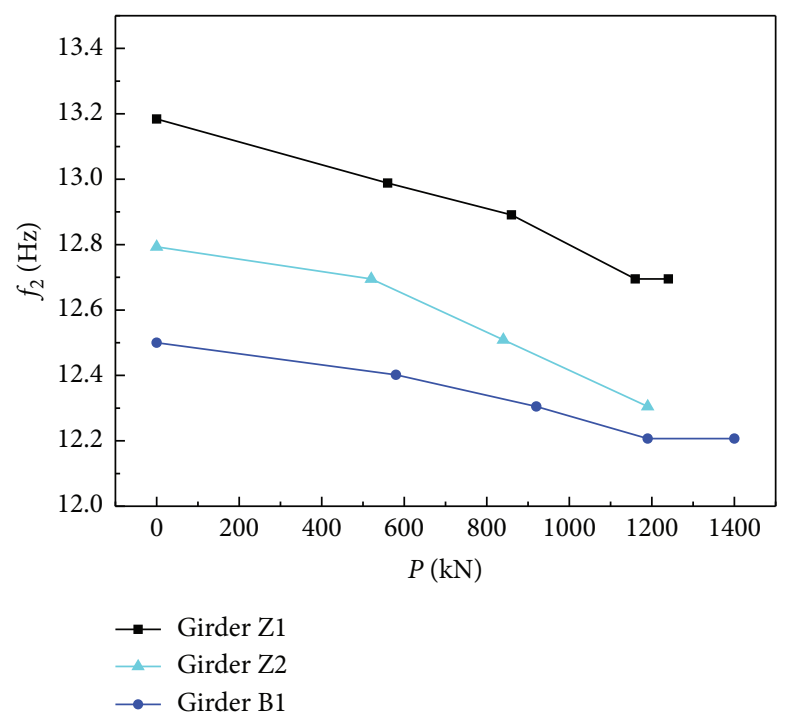

(b)

Figure 10: Natural frequencies of the test girders. (a) The first frequency. (b) The second frequency.

TABLE 5: Natural frequencies of the test girders.

\begin{tabular}{ccccc}
\hline Girder & Damage degree & $f_{2} / f_{1}$ & $\Delta f_{1} / f_{1}^{D_{0}}(\%)$ & $\Delta f_{2} / f_{2}^{D_{0}}(\%)$ \\
\hline \multirow{4}{*}{ Z1 } & $D_{0} / \mathrm{LC} 0$ & 3.649 & 0 & 0 \\
& $D_{1} / \mathrm{LC} 1$ & 3.694 & 2.685 & 1.487 \\
& $D_{2} / \mathrm{LC} 2$ & 3.772 & 5.397 & 2.121 \\
& $D_{3} / \mathrm{LC} 3$ & 3.824 & 8.110 & 3.709 \\
& $D_{4} / \mathrm{LC} 4$ & 3.824 & 8.110 & 3.709 \\
\hline \multirow{4}{*}{$\mathrm{Z} 2$} & $D_{0} / \mathrm{LC} 0$ & 3.639 & 0 & 0 \\
& $D_{1} / \mathrm{LC} 1$ & 3.714 & 2.787 & 0.766 \\
& $D_{2} / \mathrm{LC} 2$ & 3.768 & 5.575 & 2.220 \\
& $D_{3} / \mathrm{LC} 3$ & 3.818 & 8.333 & 3.815 \\
& $D_{4} / \mathrm{LC} 4$ & 3.818 & 8.333 & 3.815 \\
\hline \multirow{4}{*}{$\mathrm{B} 1$} & $D_{0} / \mathrm{LC} 0$ & 3.555 & 0 & 0 \\
& $D_{1} / \mathrm{LC} 1$ & 3.628 & 2.787 & 0.784 \\
& $D_{2} / \mathrm{LC} 2$ & 3.706 & 5.575 & 1.560 \\
& $D_{3} / \mathrm{LC} 3$ & 3.787 & 8.333 & 2.344 \\
& $D_{4} / \mathrm{LC} 4$ & 3.787 & 8.333 & 2.344 \\
\hline
\end{tabular}

emphasizes the importance of discussing elastic constraint conditions.

For the test girders, $K_{L}=K_{R}=0$, substituting it into equation (10), then $\beta_{1}=0.9922$ and $\beta_{2}=0.9644$, which resulted in $\left(\omega_{2} / \omega_{1}\right)=\left(f_{2} / f_{1}\right)=3.888$. If the stiffness of the boundary condition is far greater than that of the girder (in other words, if the test girder is the idealized simply supported girder), then $f_{2} / f_{1}$ should be 4 . Again, this result reveals that the boundary of the test girder is not equal to the idealized simply supported girder.

Table 5 shows that $f_{2} / f_{1}$ approaches the theoretical value of 3.888 as damage increases, and it also shows that $f_{2} / f_{1}$ eventually reaches 4 , which demonstrates that the boundary becomes much harder than the girder. Because the stiffness of the boundary condition is constant, it illustrates that the stiffness of the girder becomes relatively smaller, that is, the dynamic stiffness decreases.

\section{Static and Dynamic Stiffness Comparison}

6.1. Equivalent Flexural Rigidity of Girders. The design stiffness of midspan was the flexural rigidity obtained from the design drawings, in which $E$ is multiplied by $I$. The designed stiffness of the three girders are listed in Table 6 . The test girders are in the elastic stage during the first load case (LCO), illustrating the initial equivalent flexural rigidity of the structure can be obtained using equation (2). The initial equivalent flexural rigidity of the girders is also listed in Table 6. One can see that the average equivalent flexural rigidity is lower than the designed stiffness values.

In the other LCs, the equivalent flexural rigidity was also calculated based on beam deflection, as shown in Table 7 and Figure 12.

Table 7 lists the variation rates of equivalent flexural rigidity, in which, the variation rate of equivalent flexural rigidity is defined as $\left(\Delta E I_{s} / E I_{s}^{D_{0}}\right)=100 \times\left(\left(E I_{s}^{D_{0}}-E I_{s}^{D_{i}}\right) /\right.$ $\left.E I_{s}^{D_{0}}\right)(i=1,2, \ldots$,$) for the test girders. One can see that, in$ the first LCs (damage degree $D_{1}$ ), the equivalent flexural rigidity is reduced by approximately $35 \sim 50 \%$. When the ultimate load (damage degrees $D 3$ and $D 4$ ) is reached, the equivalent flexural rigidity of girder $\mathrm{Z} 1$, girder $\mathrm{Z} 2$, and girder $\mathrm{B} 1$ is reduced by $68.6 \%, 71.2 \%$, and $65.8 \%$, respectively.

It can be known from the literature [16] that the equivalent flexural rigidity of cracked girders in China can be calculated by the following equation:

$$
\begin{aligned}
B & =\frac{B_{0}}{\left(M_{c r} / M_{s}\right)^{2}+\left[1-\left(M_{c r} / M_{s}\right)^{2}\right] \cdot\left(B_{0} / B_{c r}\right)}, \\
B_{0} & =0.95 E_{c} I_{0}, \\
B_{c r} & =E_{c} I_{c r}, \\
M_{c r} & =\left(\sigma_{p c}+\gamma f_{t k}\right) \cdot W_{0},
\end{aligned}
$$




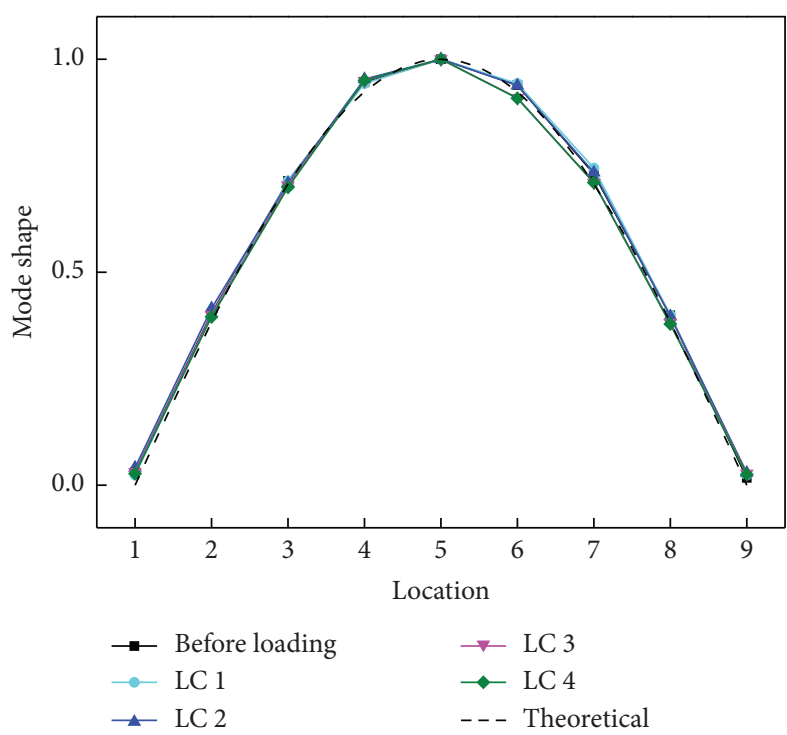

(a)

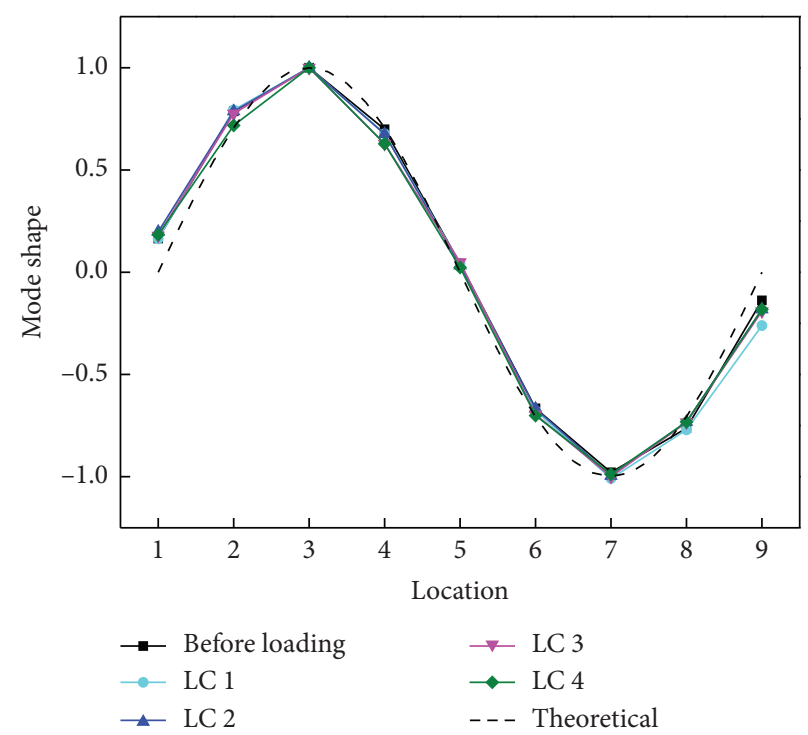

(b)

Figure 11: Test natural frequencies and mode shapes for girder Z1. (a) Mode 1. (b) Mode 2.

Table 6: Designed stiffness and initial stiffness of test girders $\left(10^{10} \mathrm{~N} \cdot \mathrm{m}^{2}\right)$.

\begin{tabular}{lccc}
\hline Girder & Designed stiffness & Initial equivalent flexural rigidity & Initial dynamic stiffness \\
\hline $\mathrm{Z} 1$ & 1.25 & 1.07 & 1.210 \\
$\mathrm{Z} 2$ & 1.25 & 1.00 & 1.146 \\
$\mathrm{~B} 1$ & 1.27 & 1.04 & 1.146 \\
\hline
\end{tabular}

TABLE 7: Equivalent flexural rigidity of the test girders under different damage conditions.

\begin{tabular}{|c|c|c|c|c|c|}
\hline Girder & Damage degree & $P(\mathrm{kN})$ & $\delta(\mathrm{mm})$ & $E I_{s}\left(10^{10} \mathrm{~N} \cdot \mathrm{m}^{2}\right)$ & $\Delta E I_{s} / E I_{s}^{D_{0}}(\%)$ \\
\hline \multirow{5}{*}{$\mathrm{Z} 1$} & $D_{0} / \mathrm{LC} 0$ & 120 & 5.0 & 1.070 & 0 \\
\hline & $D_{1} / \mathrm{LC} 1$ & 560 & 35.78 & 0.701 & 34.5 \\
\hline & $D_{2} / \mathrm{LC} 2$ & 820 & 97.54 & 0.375 & 65.0 \\
\hline & $D_{3} / \mathrm{LC} 3$ & 1160 & 150.49 & 0.344 & 67.9 \\
\hline & $D_{4} / \mathrm{LC} 4$ & 1240 & 164.62 & 0.336 & 68.6 \\
\hline \multirow{5}{*}{$\mathrm{Z} 2$} & $D_{0} / \mathrm{LC} 0$ & 72 & 3.2 & 1.000 & 0 \\
\hline & $D_{1} / \mathrm{LC} 1$ & 520 & 48.48 & 0.479 & 52.1 \\
\hline & $D_{2} / \mathrm{LC} 2$ & 840 & 108.22 & 0.346 & 65.4 \\
\hline & $D_{3} / \mathrm{LC} 3$ & 1190 & 182.89 & 0.290 & 71.0 \\
\hline & $D_{4} / \mathrm{LC} 4$ & 1190 & 184.25 & 0.288 & 71.2 \\
\hline \multirow{5}{*}{ B1 } & $D_{0} / \mathrm{LC} 0$ & 51 & 2.2 & 1.040 & 0 \\
\hline & $D_{1} / \mathrm{LC} 1$ & 580 & 41.65 & 0.622 & 40.2 \\
\hline & $\mathrm{D}_{2} / \mathrm{LC} 2$ & 920 & 98.79 & 0.416 & 60.0 \\
\hline & $D_{3} / \mathrm{LC} 3$ & 1190 & 141.74 & 0.375 & 63.9 \\
\hline & $D_{4} / \mathrm{LC} 4$ & 1400 & 175.42 & 0.356 & 65.8 \\
\hline
\end{tabular}

where $B$ is the equivalent flexural rigidity of cracked girders, $B_{0}$ is the full section flexural rigidity of girders, $B_{c r}$ is the section flexural rigidity of cracking girders, $M_{c r}$ is the cracking moment of the girder, $M_{s}$ is the bending moment under loading, $E_{c}$ is the elastic modulus of concrete, $I_{0}$ is the moment of inertia of the transformed section, $I_{c r}$ is the conversion moment of inertia of cracked section transformed to concrete, $\sigma_{p c}$ is the effective prestressing stress of concrete caused by preloading, $\gamma$ is the plastic influence factor of concrete in the compression zone, $f_{t k}$ is the tensile strength of concrete, and $W_{0}$ is the elastic resistance moment of the converted section to tensile edge.

The effective moment of inertia method is used to calculate the equivalent flexural rigidity in American Concrete Institute [17]. The equivalent flexural rigidity is as follows:

$$
\begin{gathered}
B=E_{c} \cdot I_{e} \\
I_{e}=\left(\frac{M_{c r}^{\prime}}{M_{s}}\right)^{3} \cdot I_{g}+\left[1-\left(\frac{M_{c r}^{\prime}}{M_{s}}\right)^{3}\right] \cdot I_{c r}
\end{gathered}
$$




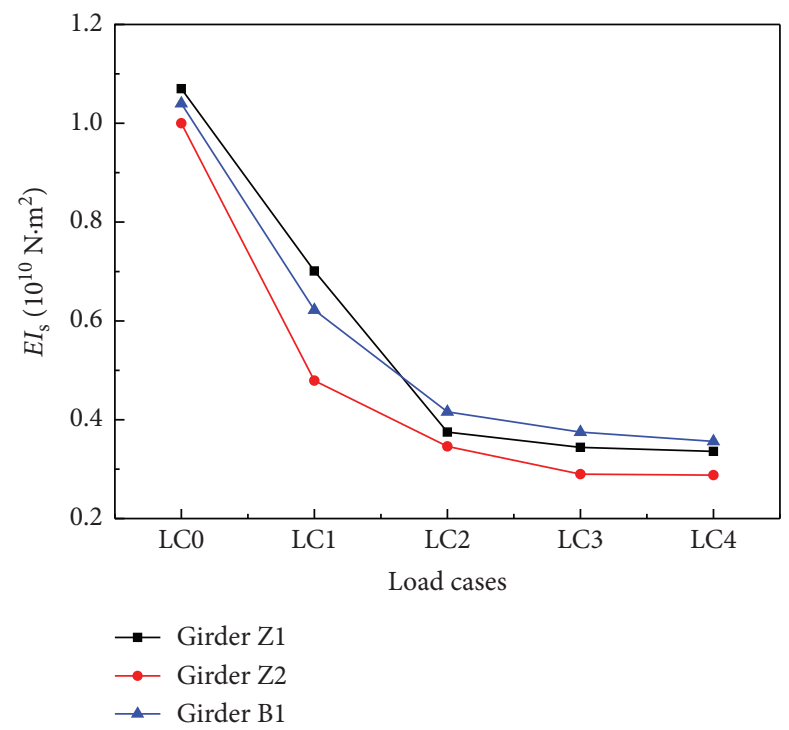

FIGURE 12: Equivalent flexural rigidity of three girders.

$$
M_{c r}^{\prime}=N_{p} \cdot e_{p}+\frac{N_{p} \cdot I_{0}}{A_{0} \cdot y_{b}}+\frac{f_{r} \cdot I_{0}}{y_{b}},
$$

where $I_{e}$ is the effective moment of inertia, $I_{g}$ is the moment of inertia of section, $M_{c r}^{\prime}$ is the cracking moment of girder, $N_{p}$ is the prestressing force produced by the prestressing tendons, $e_{p}$ is the distance between the resultant action point of the prestressing tendons and the center of gravity axis of the section, $A_{0}$ is the area of the transformed section, $y_{b}$ is the distance from the center of gravity axis of the section to the concrete in the tension zone, and $f_{r}$ is the flexural and tensile strength of concrete.

Comparisons of different equivalent flexural rigidity calculation methods for the cracked girders under different loading cases are shown in Figure 13.

From Figure 13, it can be seen that the equivalent flexural rigidity based on measured load deflection is less than the equivalent flexural rigidity calculated by China code (equation (14)) and American code (equation (18)) under different loading cases. The reason may be that the girder had cracked during its service time, which led to the decrease in the flexural rigidity of the girder. It is also pointed out that the equivalent flexural rigidity calculated by equation (18) is larger than that calculated by equation (14), which indicates that there are differences in the calculation of equivalent flexural stiffness between Chinese and American codes.

6.2. Dynamic Stiffness of Girders. Dynamic stiffness was calculated using equation (12). The initial dynamic stiffness of three girders is listed in Table 6. Other experimentally determined dynamic stiffness of test girders is presented in Table 8 and Figure 14.

In Table 8, dynamic stiffness variation is defined as $\left(\Delta E I_{d} / E I_{d}^{D_{0}}\right)=100 \times\left(\left(E I_{d}^{D_{0}}-E I_{d}^{D_{i}}\right) / E I_{d}^{D_{0}}\right)(i=1,2, \ldots$,$) for$ the test girders. One can see that, in the first LCs, the dynamic stiffness is reduced by approximately $5 \sim 6 \%$. The final dynamic stiffness values of girder $\mathrm{Z} 1$, girder $\mathrm{Z} 2$, and girder $\mathrm{B} 1$ are reduced by $15.6 \%, 15.9 \%$, and $15.9 \%$ compared to the initial ones, respectively.

6.3. Comparison of the Static and Dynamic Stiffness Values of the Girders. From Table 6, it can be observed that the initial dynamic stiffness is approximately $11 \sim 15 \%$ greater than the initial equivalent flexural rigidity. However, the dynamic stiffness of the test girders under the same damage degree is much greater than the equivalent flexural rigidity, showing the equivalent flexural rigidity of the test girders decreases faster than the dynamic stiffness. From Figure 15, one can see that the ratios between the static and dynamic stiffness of the test girders increase with load. In other words, the differences between the static and dynamic stiffness become greater as the load increases. The ultimate dynamic stiffness of girder Z1, girder Z2, and girder B1 is 3.042, 3.344, and 2.705 times the equivalent flexural rigidity, respectively. The reason was explained by the fact that the steel-concrete bonds were destroyed when the load acted on the structure during the static tests, which led to abundant microcosmic and macroscopic cracks. The dynamic tests were performed after unloading for each LC of the static tests. Prestressing can improve the stiffness of girders. Prestressing can delay the occurrence of cracks and effectively improve the service performance. From the load-deflection curve (Figure 9), it can be seen that when unloaded, the displacements could be recovered before LC3, and the crack could be partly closed, which means that the girder remains at the elastic stage and there is no yielding of prestressing tendon. As a result, the inertial moment can be partly restored and the dynamic stiffness in the case can be greater than that of the static one.

In the specimen scale-down model test [18], dynamic stiffness of the model beam is $15.2 \%$ greater than the 

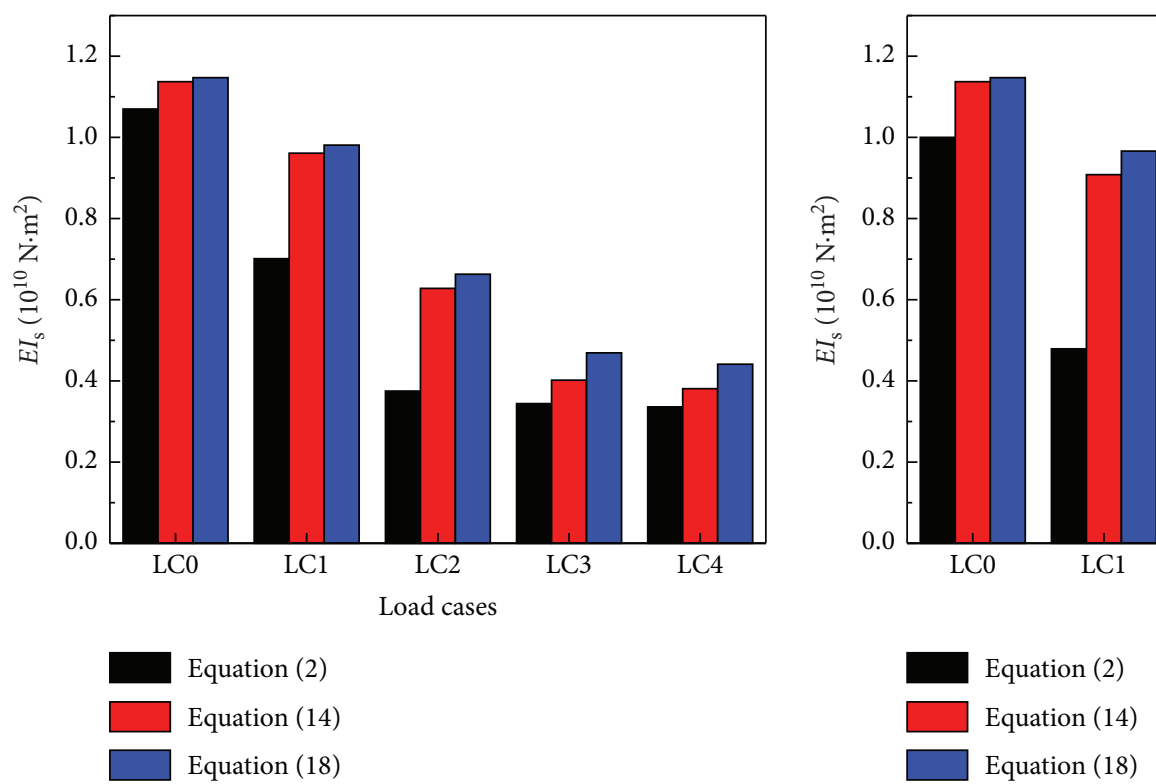

(a)

(b)

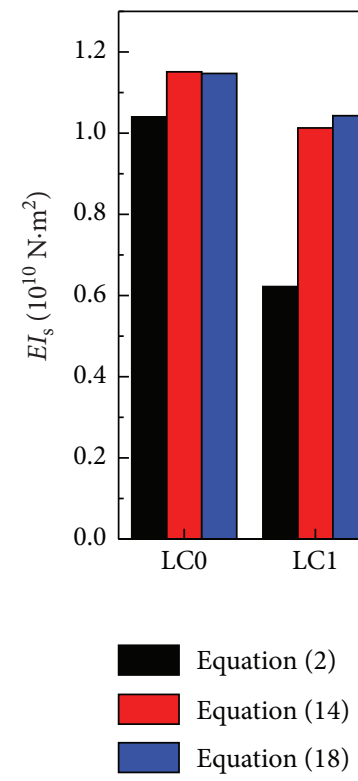

(c)

Figure 13: Comparisons of each equivalent flexural rigidity calculation method for test girder. (a) Girder Z1. (b) Girder Z2. (c) Girder B1.

equivalent flexural rigidity before cracking of beams, which is consistent with our results. However, the ultimate variation rate of equivalent flexural rigidity before failure of the scale-down model beams is only $50 \%$ compared with its initial one and dynamic stiffness is $72 \%$ compared with its initial one, which is different from our results. The differences lie in that the dynamic elastic modulus of prestressed concrete beams is larger than the static elastic modulus, and the dynamic damage identification and the target quantity of static damage are different in the literature. Another reason may be that boundary support conditions of scale-down model result in the identification difference of frequencies which will lead to identification difference of dynamic stiffness of test beams.

6.4. Discussion. There is some uncertainty in the results: the concrete is sawed from the end of the girder, which may not stand for the majority of the concrete of the girder, and the flexural rigidity used by the code method would be more precise if the effective prestressing stress of concrete was tested. There are only three girders in which it is difficult to get the statistical equivalent flexural rigidity and appropriate confidence limits. 
TABle 8: Dynamic stiffness of the test girders under different damage conditions.

\begin{tabular}{ccccc}
\hline Girder & $\begin{array}{c}\text { Damage } \\
\text { degree }\end{array}$ & $\begin{array}{c}f_{1} \\
(\mathrm{~Hz})\end{array}$ & $\begin{array}{c}E I_{d} \\
\left(10^{10} \mathrm{~N} \cdot \mathrm{m}^{2}\right)\end{array}$ & $\begin{array}{c}\Delta E I_{d} / E I_{d}^{D_{0}} \\
(\%)\end{array}$ \\
\hline \multirow{4}{*}{$\mathrm{Z} 1$} & $D_{0} / \mathrm{LC} 0$ & 3.613 & 1.210 & 0 \\
& $D_{1} / \mathrm{LC} 1$ & 3.516 & 1.146 & 5.3 \\
& $D_{2} / \mathrm{LC} 2$ & 3.418 & 1.083 & 10.6 \\
& $D_{3} / \mathrm{LC} 3$ & 3.320 & 1.022 & 15.6 \\
& $D_{4} / \mathrm{LC} 4$ & 3.320 & 1.022 & 15.6 \\
\hline \multirow{4}{*}{$\mathrm{Z} 2$} & $D_{0} / \mathrm{LC} 0$ & 3.516 & 1.146 & 0 \\
& $D_{1} / \mathrm{LC} 1$ & 3.418 & 1.083 & 5.6 \\
& $D_{2} / \mathrm{LC} 2$ & 3.320 & 1.022 & 10.9 \\
& $D_{3} / \mathrm{LC} 3$ & 3.223 & 0.963 & 15.9 \\
& $D_{4} / \mathrm{LC} 4$ & 3.223 & 0.963 & 15.9 \\
\hline \multirow{4}{*}{ B1 } & $D_{0} / \mathrm{LC} 0$ & 3.516 & 1.146 & 0 \\
& $D_{1} / \mathrm{LC} 1$ & 3.418 & 1.083 & 5.6 \\
& $D_{2} / \mathrm{LC} 2$ & 3.320 & 1.022 & 10.9 \\
& $D_{3} / \mathrm{LC} 3$ & 3.223 & 0.963 & 15.9 \\
& $D_{4} / \mathrm{LC} 4$ & 3.223 & 0.963 & 15.9 \\
\hline
\end{tabular}

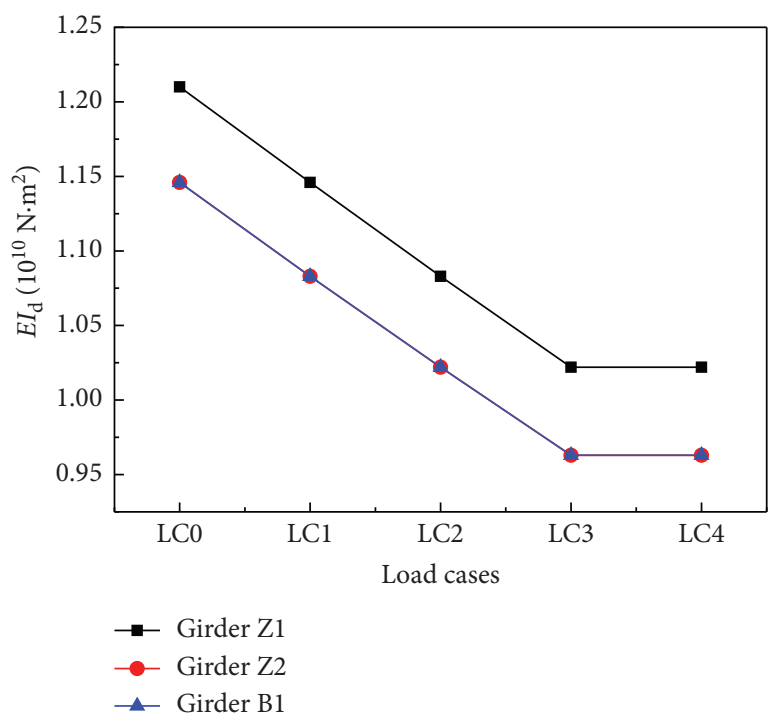

Figure 14: Dynamic stiffness of three girders.

\section{Conclusion}

(1) Equivalent flexural rigidity was determined based on deflection, and the equivalent flexural rigidity of the test girders decreased rapidly at the starting of the loading stage. The final equivalent flexural rigidity of the beams was approximately $30 \%$ of the initial stiffness.

(2) Dynamic stiffness was calculated by frequencies under elastomeric bearing conditions. The ultimate fundamental frequencies for girders $\mathrm{Z} 1, \mathrm{Z} 2$, and $\mathrm{B} 1$ with respect to the damage $D_{0}$ were $8.11 \%$, $8.33 \%$, and $8.33 \%$, respectively. The ultimate variation frequencies of the three test girders were almost the same. Additionally, the first frequency

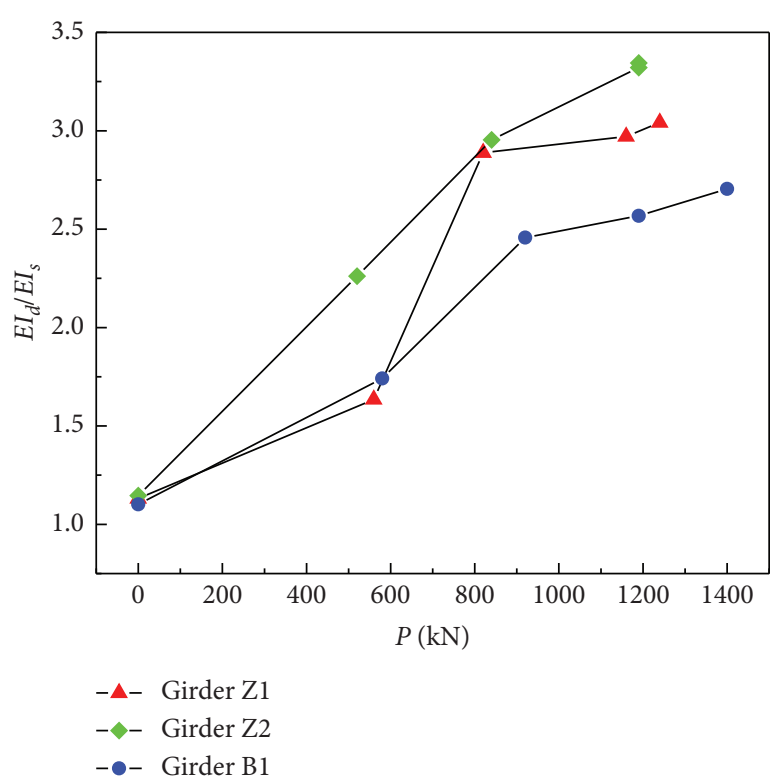

FIGURE 15: Ratio of dynamic stiffness to equivalent flexural rigidity.

was more sensitive to cracking than the second frequency.

(3) Originally, the test girder for the purpose of dynamic analysis cannot be simplified as the ideal simply supported beam. With the increase of damage, the boundary conditions of the test beam become close to that of the ideal simply supported beam.

(4) The ultimate dynamic stiffness values of the girders were approximately $84 \%$ of the initial dynamic stiffness values.

(5) There was little difference between the initial static and dynamic stiffness values of the girders before loading. However, the percentages of static and dynamic stiffness reduction were not equal under different levels of damage.

\section{Data Availability}

The data used to support the findings of this study are included within the article.

\section{Conflicts of Interest}

The authors declare that they have no conflicts of interest.

\section{Acknowledgments}

This work was supported by Shaanxi Provincial Science Foundation (Grant no. 2019JM-362) and the National Science Foundation of China (Grant no. 51678061 and 51978063). Their financial support is greatly appreciated. The authors thank Liu Wanfeng and Zhou Ying for their assistance during the field test. 


\section{References}

[1] A. Castel, R. I. Gilbert, and G. Ranzi, "Instantaneous stiffness of cracked reinforced concrete including steel-concrete interface damage and long-term effects," Journal of Structural Engineering, vol. 140, no. 6, pp. 1299-1328, 2014.

[2] A. Castel, T. Vidal, and R. François, "Finite-element modeling to calculate the overall stiffness of cracked reinforced concrete beams," Journal of Structural Engineering, vol. 138, no. 7, pp. 889-898, 2012.

[3] X. Zhao, Y. R. Zhao, X. Z. Gao, X. Y. Li, and Y. H. Li, “Green's functions for the forced vibrations of cracked Euler-Bernoulli beams," Mechanical Systems and Signal Processing, vol. 68-69, pp. 155-175, 2016.

[4] T. Xu, L. Zhu, A. Castel, and R. I. Gilbert, "Assessing immediate and time-dependent instantaneous stiffness of cracked reinforced concrete beams using residual cracks," Journal of Structural Engineering, vol. 144, no. 4, 2018.

[5] T. Xu and A. Castel, "Modeling the dynamic stiffness of cracked reinforced concrete beams under low-amplitude vibration loads," Journal of Sound and Vibration, vol. 368, pp. 135-147, 2016.

[6] T. Xu, J. Huang, A. Castel, R. Zhao, and C. Yang, "Influence of steel-concrete bond damage on the dynamic stiffness of cracked reinforced concrete beams," Advances in Structural Engineering, vol. 21, no. 3, pp. 1977-1989, 2018.

[7] P. C. Das, J. S. Owen, B. J. Eccles, M. A. Woodings, and B. S. Choo, "Role of dynamic testing in assessment of bridges," Transportation Research Record: Journal of the Transportation Research Board, vol. 1594, no. 1, pp. 115-124, 1997.

[8] W.-X. Ren and G. De Roeck, "Structural damage identification using modal data. I: simulation verification," Journal of Structural Engineering, vol. 128, no. 1, pp. 87-95, 2002.

[9] W.-X. Ren and G. De Roeck, "Structural damage identification using modal data. II: test verification," Journal of Structural Engineering, vol. 128, no. 1, pp. 96-104, 2002.

[10] M. Musiał, "Laboratory tests of reinforced concrete beams with the use of operational modal analysis," Materials Science Forum, vol. 866, pp. 124-128, 2016.

[11] R. Capozucca, "A reflection on the application of vibration tests for the assessment of cracking in PRC/RC beams," Engineering Structures, vol. 48, pp. 508-518, 2013.

[12] R. Capozucca, J. Domizi, and E. Magagnini, "Damaged RC beams strengthened with NSM CFRP rectangular rods under vibration in different constrain conditions," Composite Structures, vol. 154, pp. 660-683, 2016.

[13] J. Zhang, H. Peng, and C. S. Cai, "Destructive testing of a decommissioned reinforced concrete bridge," Journal of Bridge Engineering, vol. 18, no. 6, pp. 564-569, 2013.

[14] R. Capozucca and S. Bossoletti, "Static and free vibration analysis of RC beams with NSM CFRP rectangular rods," Composites Part B: Engineering, vol. 67, pp. 95-110, 2014.

[15] Y. Zhou, Z. J. Ma, Y. Zhao, X. Shi, and S. He, "Improved definition of dynamic load allowance factor for highway bridges," Structural Engineering and Mechanics, vol. 54, no. 3, pp. 561-577, 2015.

[16] JTG 3362-2018, Specifications for Design of Highway Reinforced Concrete and Prestressed Concrete Bridges and Culverts, China Communications Highway Planning and Design Institute Co., Ltd., Beijing, China, 2018.

[17] American Concrete Institute, Building Code Requirements for Structural Concrete (ACI 318M-08) and Commentary (ACI 318RM08), American Concrete Institute, Farmington Hills, MI, USA, 2008.

[18] W. J. Yi, Y. Zhou, and B. Cao, "Static and dynamic experiment study and stiffness identification of an unbounded prestressed concrete beam," Journal of Vibration and Shock, vol. 27, no. 1, pp. 71-75, 2008. 


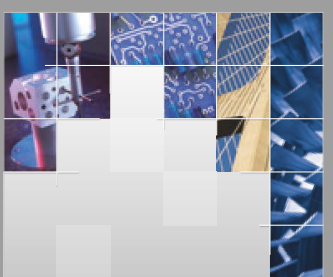

\section{Enfincering}
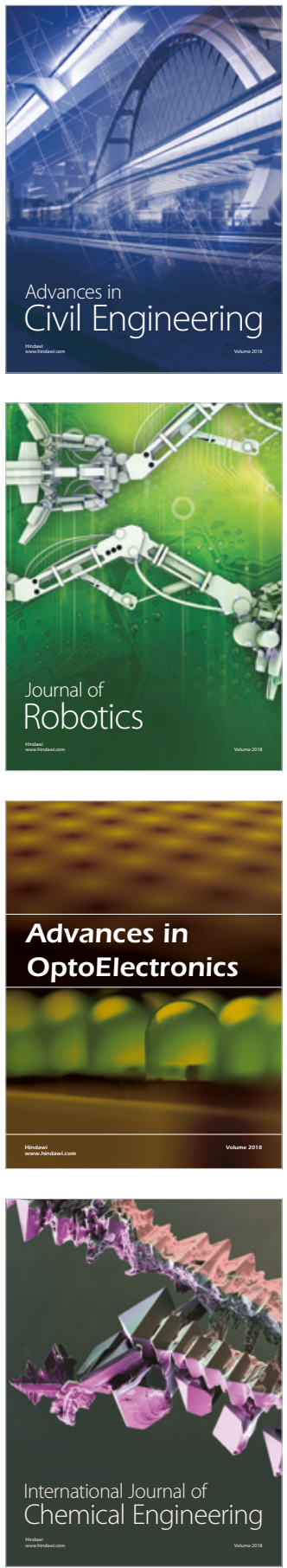

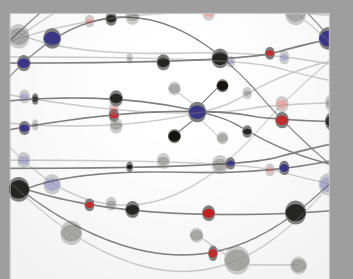

\section{Rotating \\ Machinery}

The Scientific World Journal

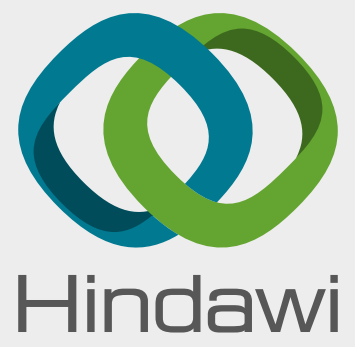

Submit your manuscripts at

www.hindawi.com
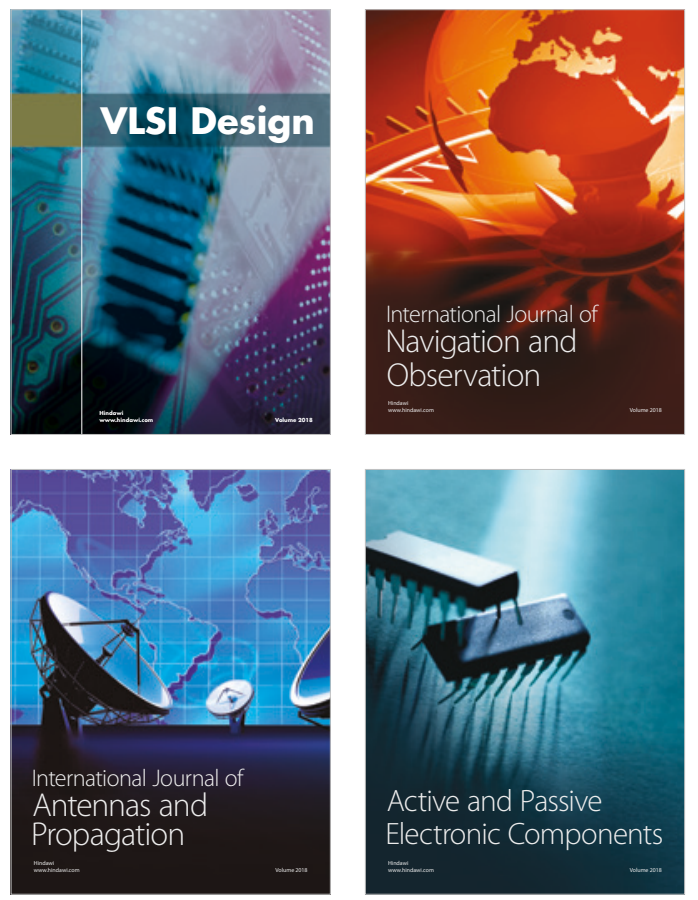
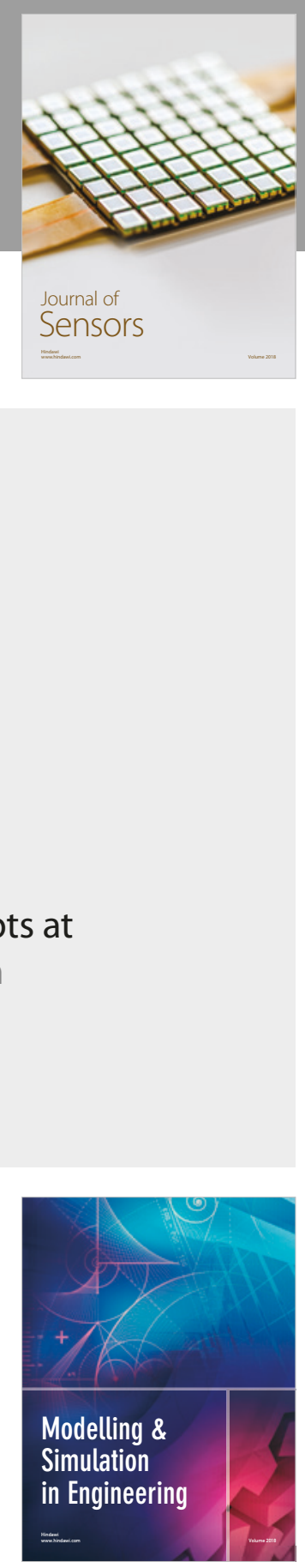

\section{Advances \\ Multimedia}
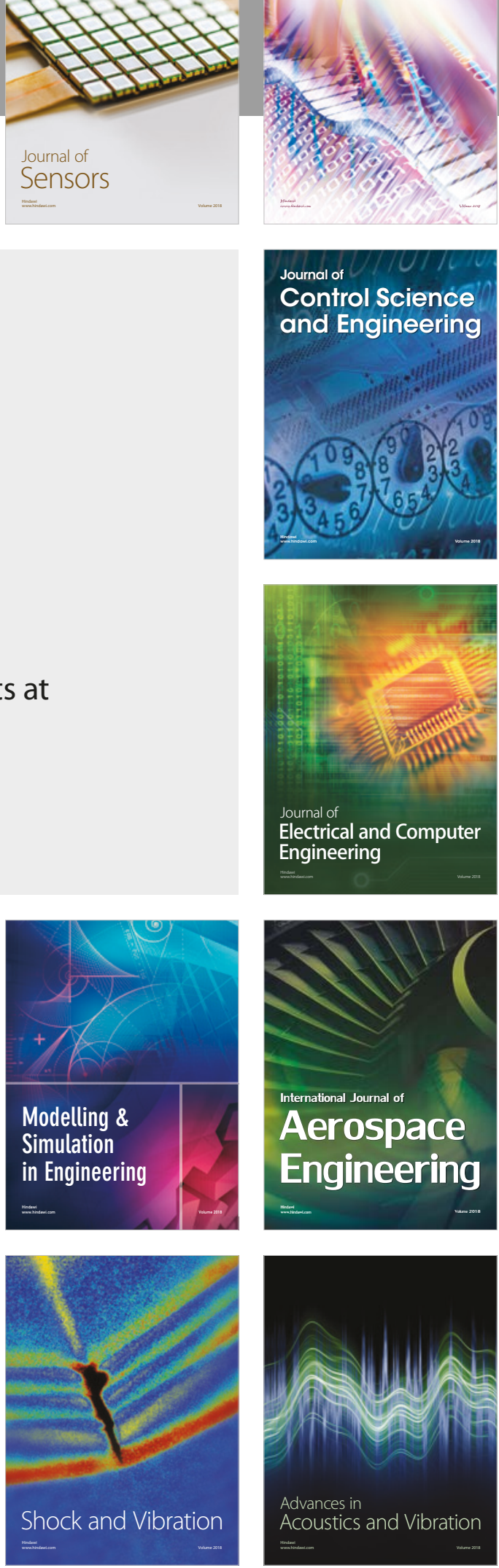